\title{
Introduction to the Handbook of Theories of Public Administration and Management
}

\author{
Thomas A. Bryer
}

When invited to edit this Handbook, I agreed with three primary goals: (1) that the chapters reflect the broad issues, concerns and theoretical perspectives across the public administration and management scholarly community, (2) that the authors include internationally known senior scholars as well as early- and mid-career junior scholars to capture the broad historical perspectives that come with experience and the fresh approaches advanced by those who were socialized into the discipline by reading some of these same senior scholars, and (3) that the authors represent a cross-section of the world, so that the final Handbook is not a product relevant only for scholars and students in the United States or in Western societies but throughout the world. Within these pages are 26 chapters written by 39 authors/co-authors and representing 13 countries. Authors/co-authors include recently minted $\mathrm{PhD}$ students and current $\mathrm{PhD}$ students, mid-career associate professors, and senior scholars whose work is foundational to the considered topics.

The Handbook is broken into five parts, though readers of the full volume will find clear relationships across both chapters within each part and across parts. In this Introduction, I suggest where some of these linkages exist. First, I describe the plan of the book.

Part I concerns theories on the role of public administration. As a field of practice, the purpose of public administration in society has been and remains contested. Indeed, defining public administration itself and the values that give it and the people who work within it their identity are not only contested but, in some cases, in conflict with each other.

In Chapter 1, Patrick Overeem from Vrije University Amsterdam in the Netherlands considers the role of public administration vis-à-vis politics, as an art of separation. He concludes that administration must not be either separated from nor subordinate to politics but be both simultaneously, and the key to achieving this balance is administrative discretion. As he writes in the chapter, "administrative values need protections against encroachment by politics, political values against encroachments by administration, and above all constitutional values against encroachments by the state as a whole." This requires a careful negotiation across legitimate interests and concerns of both public administrators and those who are more strictly defined as existing within the political sphere. The idea of negotiation is advanced further in the second chapter by Thomas Bryer and Nina Alvandipour of the University of Central Florida in the United States.

Bryer and Alvandipour consider public administration and citizen participation. Consistent with Overeem's identified challenge for public administration to be multiple things and have multiple identities simultaneously, Bryer and Alvandipour suggest that public administration and public administrators must simultaneously be open to being influenced by the will of the people and also protected from being subservient to that will. After reviewing historical and contemporary perspectives on the question, they conclude that the path forward is to develop mutual skepticism between citizens and public administrators. 


\section{Handbook of theories of public administration and management}

Conflicts in the purpose and role of public administration and the individual public administrator create potential ethical dilemmas. In Chapter 3, So Hee Jeon from Central Michigan University in the United States provides a map of research and knowledge accumulation related to public administration and public service ethics. She reviews research from the principle level, exploring the ethical grounds for public administration, as well as the operational level, which considers the mechanism to achieve an ethical public administration. She calls on leading thinkers in the field in her exploration of ethical decision-making, virtue ethics, and the very essence of what is ethical government.

Chapters 4 and 5, the final chapters in Part I, consider the purpose of public administration as a manifestation and facilitator of social equity and social justice in government, and through government, in the broader society. These chapters can be fruitfully read in combination with Chapters 16 and 17 on diversity and gender in public organizations.

Susan Gooden from Virginia Commonwealth University in the United States and Anthony Starke from the University of Colorado Denver in the United States focus on four theories of social equity: Theory of Justice, Organizational Justice, Compound Theory of Social Equity, and Targeted Universalism. Significantly, they consider the practical implications of these theories on public administration practice while also examining the tradeoffs of application.

Kareem Willis from Rutgers University - Newark in the United States and Tia Sherèe Gaynor from the University of Cincinnati in the United States pursue justice considerations with a deeper assessment and integration of voices of those who have not received as much attention to date in scholarly literature or practical application. They consider a host of theories in their discussion of social justice in public administration: Critical Race Theory, Black Feminist Theory, Queer Theory, Power and Privilege.

Part II includes six chapters focused on theories on the function of public administration. Contrasted with the preceding chapters that focused on fundamental purpose within society, these chapters consider more specific functions, which can support the realization of the purposes outlined in the first part. Topics in this part consist of government performance, collaborative governance, public sector branding, digital government, administrative law, and municipal management.

In Chapter 6, Kathryn Newcomer from George Washington University in the United States and Clint Brass, currently a Specialist in Government Organization and Management at the Congressional Research Service in the United States Library of Congress, discuss ways in which performance in the public sector may be conceptualized. They argue through a review of historical and contemporary literature that government performance be viewed as multi-dimensional and informed by values that may include tradeoffs in practice.

Sofia Prysmakova-Rivera from Kennesaw State University in the United States and Olga Pysmenna from the University of Central Florida in the United States consider in Chapter 7 how government performance and outcomes can best be achieved through collaborative processes. They develop a model for how collaborative governance can serve the public, through which processes and towards what outcomes.

Staci Zavattaro of the University of Central Florida and Blair Thomas of Valdosta State University in the United States provide an overview in Chapter 8 on the state of theory and practice in public sector branding. People, images, and policies of an agency or jurisdiction are powerful tools to communicate mission, emphasize aspects of culture, and promote attributes that burnish the reputation to advance mission, quality of life, and other outcomes. They leave the chapter with a set of research questions to guide ongoing work in this area. 
Branding in the digital sphere is one area that has been and will continue to be explored. More broadly, the availability and use of digital government tools have transformed public administration and public service organization practice. In Chapter 9, Qianli Yuan and Mila Gasco-Hernandez from the University at Albany, State University of New York, and J. Ramon Gil-Garcia from Universidad de las Américas Puebla in Mexico review analytical models, underlying theories, and emergent theoretical perspectives regarding digital government. They observe that much research in the area of digital government is atheoretical and entirely pragmatic, which they address in terms of implication and future directions for the field.

Also pragmatic without broad theory in all cases is the examination and practice of administrative law. In Chapter 10, Stephanie Newbold from Rutgers University - Newark in the United States explores the origins of administrative law and the importance of agency rules to the public policy process. She grounds the emergence of administrative law in the United States through the Administrative Procedures Act, which established principles of rulemaking, adjudication, and judicial review. She argues that understanding administrative law is essential for public sector managers as a means of mission pursuit and achievement.

In the final chapter in Part II, Kimberly Nelson from the University of North Carolina at Chapel Hill in the United States reviews the research on municipal management and form of government. She proposes a theoretical foundation to distinguish two major forms: council-manager and mayor-council. With her framework, Nelson indicates the need for future research on how form affects governance outcomes and procedures, including finance, innovation, corruption, and conflict.

Part III focuses on theories on the people in public administration, as contrasted with the purposes, forms, and functions of public administration covered in the preceding parts. This part contains six chapters and addresses public service motivation, personnel management, religiosity, leadership, diversity, and gender.

In Chapter 12, Palina Prysmakova of Florida Atlantic University in the United States reviews and critiques theories and research on public service motivation (PSM). Rather than providing a comprehensive review of PSM - its antecedents and consequences, and measurement scales - Prysmakova questions the underlying utility of PSM as a field of research. The motivation of public service employees is also addressed, along with other human resource management (HRM) theories in Chapter 13. Mauricio Astudillo-Rodas and Norma Riccucci from Rutgers University - Newark in the United States review key theories in HRM, including Representative Bureaucracy, Social Exchange Theory, and Ability, Motivation and Opportunity Theory. Astudillo-Rodas and Riccucci examine how these theories align with individual and organizational interest to improve performance.

As there are different factors that motivate individuals differently in the public sector workforce, religious differences introduce diverse values into professional practice. Daniel Hummel from University of Louisiana-Monroe in the United States in Chapter 14 explores the role of religion in society and public service in the United States, where he finds that religion continues to influence public policy and public administration. Hummel concludes that those who work in public service need to be prepared to work with those who share in their religious beliefs and those who do not, which, he argues, requires emphasizing those parts of religious belief that enhance public service.

In Chapter 15, Ulrich Thy Jensen from Arizona State University in the United States examines past and future research on public leadership, with an emphasis on charismatic leadership. He argues that future public leadership research on charisma should (1) focus on the unique 
and specific behaviors that engender leader charisma, (2) study its causal effect on individual and collective outcomes, and (3) facilitate ways to make charisma a learnable skill to be cultivated among existing and future leaders across all levels of government. With these future directions, Jensen maps what he considers the demise and rebirth of charisma as an important area for research.

Diversity in public service and public administration is a critical issue that unites many other streams of research and theory development in public administration and management. It unites, in that the benefits and consequences of cultivating, supporting, and sustaining diversity (or not doing so) are far-reaching for professionals, students, and citizens who are recipients of goods and services. In Chapter 16, Brandi Blessett from the University of Cincinnati in the United States explores the significance of diversity. She seeks to extend our understanding of diversity and situate diversity as the first step toward equity and inclusion, both in public administration practice and teaching.

One component of diversity and inclusion is attention paid to gender identities, both within the ranks of public administrators and the citizens served through government and partner offices. In Chapter 17, Nicole Elias and Maria D'Agostino from John Jay College in the City University of New York explore the theoretical foundations of gender in public administration scholarship. Included in their analysis is an exploration of how gender applies to management and leadership in public service organizations. They conclude with theoretically derived suggestions for gender workplace policies that ensure fair and equal treatment across genders.

New workplace policies on gender, diversity, inclusion, and so on represent for many public organizations the need for change - structural, cultural, legal, and otherwise. The first chapter in Part IV addresses this issue of evolution and change in public organizations. Part IV concerns theories on the organization of public administration; the focus is on organizational theories, rather than organizational behavior theories.

In Chapter 18, Jesse Campbell from Incheon National University in South Korea explores two models of change in public organizations: efficiency-enhancing and legitimacy-enhancing. Campbell argues that the need to secure legitimacy is the driving force of change in many public organizations, but the ability to secure genuine and lasting change is challenged by organizational processes that protect the status quo. In closing, he argues that public managers may lack strong incentives to produce desired, legitimacy-enhancing change.

In Chapter 19, Jan-Erik Johanson from Tampere University in Finland considers organizational planning and possible change with a focus on strategic management in public organizations. Johanson traces developments in strategic management from the perspectives of strategic design, internal strategic scanning, and strategic governance. This chapter can fruitfully be read in combination with the first chapter, which focuses on the separation of politics from administration, as Johanson emphasizes the importance of political struggle and bargaining in the process of strategic management.

Erik Eriksson and Andreas Hellström from Chalmers University of Technology in Sweden broaden our lens outside a single organization in Chapter 20. Here, Eriksson and Hellström examine inter-organizational collaboration and co-production. They argue that citizen-centered collaboration is essential to successfully integrate resources among multiple actors. Significantly for public administration scholars, they profile two action research cases and show the power of the action researcher to help facilitate resource integration while also contributing their own knowledge to help achieve collaborative outcomes. 
In the final part of the book, six chapters consider the various theories and perspectives introduced in the preceding parts and how they fit or might apply differently in various other countries: Chile, Lithuania, China, United Kingdom, Pakistan, India, and Russia.

In Chapter 21, Cristian Pliscoff from Catholic University in Chile focuses on three key issues: public employment, performance management systems, and the politics-administration dichotomy. This chapter can fruitfully be read in combination with Chapter 1 by Patrick Overeem, Chapter 6 by Kathryn Newcomer and Clint Brass, and Chapter 13 by Mauricio Astudillo-Rodas and Norma Riccucci.

Vitalis Nakrošis from Vilnius University in Lithuania explores, in Chapter 22, public administration reforms in that country during the period 2008-20. Consistent with some challenges identified by Campbell in Chapter 18, Nakrošis finds that administrative reform decisions are often not ambitious enough to achieve desired results and also face numerous obstacles to implementation.

In Chapter 23, Hui Li from The University of Hong Kong and Jiasheng Zhang from City University of Hong Kong explore how Chinese public administration has been researched and reported in mainstream public administration journals. Based on analysis of 209 articles between the years 2002 and 2020, they find that scholars are increasingly linking issues in Chinese public administration to broader dialogues, and the main strategy of authors is to apply Western concepts and theories to the Chinese context, with an aim to test and extend those theories.

John Diamond from Edge Hill University in the United Kingdom seeks to explain, in Chapter 24, the context of public administration and public management scholarship in his country. He argues that it is essential for historical and theoretical reasons to distinguish between public administration, on the one hand, and public management, on the other. Diamond concludes that these two frames are in competition and will shape policy choices in the United Kingdom over the next decade.

In Chapter 25, Aamer Taj and Muhammad Nouman from the Institute of Management Sciences in Pakistan examine local government reforms and decentralization in Pakistan and India. Similar to findings from Nakrošis in Chapter 22 and Campbell in Chapter 18, Taj and Nouman find numerous factors that undermine institutionalization of reform. In the context of Pakistan, these challenges include the history of authoritarianism, international political economy relations, and characteristics of the civil service. They compare these findings with the case of Kerala, a state in India, with implications for policy and future administrative reforms.

In the final chapter, Nina Symaniuk from Ural Federal University in Russia examines the transformation of public administration since the adoption of the Russian Constitution in 1993. She emphasizes the influence of digitalization of administrative processes for the administrative state and the role of public administration in the broader society. This chapter can fruitfully be read in combination with Chapter 9 on theories of digital government.

In summary, the assembled chapters in this Handbook join diverse authors from countries around the world. Individually and collectively, authors review leading and emerging theories in public administration and management, apply them to old and still relevant, as well as new and critical issues of public service and the relationship between government and the broader society. For scholars and students of public administration and management, the Handbook is a critical resource to frame the future of theory development and testing through research in the coming years. 